BMJ Open Diabetes Research \& Care

\title{
Weight loss efficacy of a novel mobile Diabetes Prevention Program delivery platform with human coaching
}

\author{
Andreas Michaelides, Christine Raby, Meghan Wood, Kit Farr, Tatiana Toro-Ramos
}

To cite: Michaelides A, Raby C, Wood M, et al. Weight loss efficacy of a novel mobile Diabetes Prevention Program delivery platform with human coaching. BMJ Open Diabetes Research and Care 2016;4:e000264.

doi:10.1136/bmjdrc-2016000264

Received 4 May 2016 Revised 19 July 2016 Accepted 11 August 2016
CrossMark

Noom, Inc., New York, New York, USA

Correspondence to Dr Andreas Michaelides; andreas@noom.com

\section{ABSTRACT}

Objective: To evaluate the weight loss efficacy of a novel mobile platform delivering the Diabetes Prevention Program.

Research Design and Methods: 43 overweight or obese adult participants with a diagnosis of prediabetes signed-up to receive a 24 -week virtual Diabetes Prevention Program with human coaching, through a mobile platform. Weight loss and engagement were the main outcomes, evaluated by repeated measures analysis of variance, backward regression, and mediation regression.

Results: Weight loss at 16 and 24 weeks was significant, with $56 \%$ of starters and $64 \%$ of completers losing over $5 \%$ body weight. Mean weight loss at 24 weeks was $6.58 \%$ in starters and $7.5 \%$ in completers. Participants were highly engaged, with $84 \%$ of the sample completing 9 lessons or more. In-app actions related to self-monitoring significantly predicted weight loss.

Conclusions: Our findings support the effectiveness of a uniquely mobile prediabetes intervention, producing weight loss comparable to studies with high engagement, with potential for scalable population health management.

\section{INTRODUCTION}

Lifestyle interventions, ${ }^{1}$ including the National Diabetes Prevention Program (NDPP) have proven effective in preventing type 2 diabetes. $^{2}{ }^{3}$ Online delivery of an adapted NDPP has resulted in high levels of engagement, weight loss, and improvements in glycated hemoglobin (HbA1c). ${ }^{4}{ }^{5}$ Prechronic and chronic care efforts delivered by other means (text and emails, ${ }^{6}$ nurse support, ${ }^{7}$ DVDs, ${ }^{8}$ community care $^{9}$ ) have also been successful in promoting behavior change, weight loss, and glycemic control. One study $^{10}$ adapted the NDPP to deliver the first part of the curriculum in-person and the remaining sessions through a mobile app, and found $6.8 \%$ weight loss at 5 months. Mobile health poses a promising means of delivering prechronic and chronic care $^{11}{ }^{12}$ and provides a scalable,

\section{Key messages}

- To the best of our knowledge, this study is the first fully mobile translation of the Diabetes Prevention Program.

- A National Diabetes Prevention Program (NDPP) intervention delivered entirely through a smartphone platform showed high engagement and 6-month transformative weight loss, comparable to the original NDPP and comparable to traditional in-person programmes.

- This pilot shows that a novel mobile NDPP intervention has the potential for scalability, and can address the major barriers facing the widespread translation of the NDPP into the community setting, such as a high fixed overhead, fixed locations, and lower levels of engagement and weight loss.

convenient, and accessible method to deliver the NDPP.

The weight loss efficacy of a completely mobile delivery of a structured NDPP has not been tested. The main aim of this pilot study was to evaluate the weight loss efficacy of Noom's smartphone-based NDPP-based curricula with human coaching in a group of overweight and obese hyperglycemic adults receiving 16 weeks of core, plus postcore curriculum. In this study, it was hypothesized that the mobile DPP could produce transformative weight loss over time.

\section{RESEARCH DESIGN AND IMETHODS}

A large Northeast-based insurance company offered its employees free access to Noom Health, a mobile-based application that delivers structured curricula with human coaches. An email or regular mail invitation with information describing the study was sent to potential participants based on an elevated HbA1c status found in their medical records, reflecting a diagnosis of prediabetes. Interested participants were assigned to a virtual Centers for Disease Control and Prevention (CDC)-recognized NDPP master's level coach. 
Hyperglycemic males and females (HbAlc between $5.7 \%$ and $6.4 \%$ ) between the ages of 18 and 75 years old who signed-up for Noom's NDPP (figure 1, n=121) between $6 / 22 / 2015$ and $9 / 7 / 2015$ were included in the study. Of 121, individuals were considered 'interested' $(n=62)$ if they performed at least one in-app action during the first week of the curriculum. From 62 interested participants, those having $<2$ weigh-ins $(n=8)$ past baseline and who did not read more than one article per week for 4 or more weeks were considered nonstarters and were excluded from final analyses. An additional subject did not provide any information.

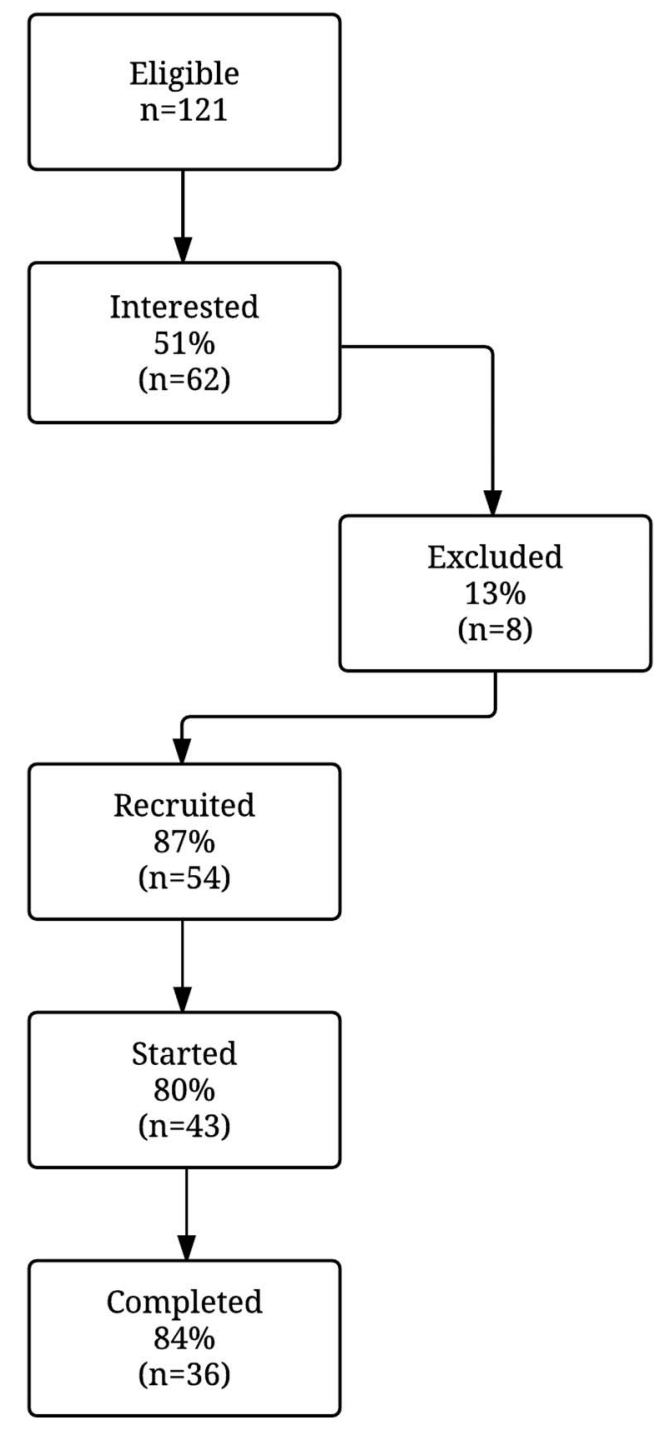

Figure 1 Flow chart for study recruitment, starting and completion status. Eligible, participants who signed-up and were included in the study; interested, individuals that performed at least one in-app action during the first week of the NDPP curriculum; recruited, participants who read at least one article during any 4 of the 16 initial weeks and also messaged the coach at least one time within the first month; completers, read at least one article per week during any 9 of the 16 weeks; excluded, participants who had $<2$ weigh-ins $(n=8)$, none of which were considered 'starters'.
Participants who read at least one article during any 4 of the 16 initial weeks were considered to have started, in accordance with the CDC's definition. 'Starters' $(n=43)$ must have also messaged the coach at least one time within the first month. 'Completers' $(n=36)$ read at least one article per week during any 9 of the 16 weeks.

During the first week of the study, participants received orientation on what the DPP entails, and learnt how to use the Noom app, interact with their coach, and the importance of maintaining motivation throughout the programme. Participants received daily DPP content through informative articles and interactive challenges, and were asked to log their weight, meals, and physical activity in-app on a weekly basis. The NDPP coach communicated with the participants daily via in-app private and group messages, and brief telephone calls approximately two times per month. Coaches securely monitored participant progress through a dashboard. The present study reports 24-week (6 month) results, including the16-week core DPP phase, followed by the first 8 weeks of the postcore DPP phase.

\section{Statistical analysis}

Descriptive statistics, expressed as means $\pm \mathrm{SD}$, were calculated for subject baseline characteristics. Independent samples t-test compared descriptive baseline characteristics among non-starters and starters. Repeated measurements analysis of variance (ANOVA) distinguished the effect of time on weight change. This method extracts the contribution of the subjects from the error term. A post hoc ANOVA method, the pairwise Fisher's exact test, examined differences from baseline for the 16-week and 24-week weights. Ad hoc ANOVA tests examined the effect size of the change in weight from baseline to 16 and 24 weeks. Backward regression analyses examined whether engagement variables predicted weight loss at 16 and 24 weeks. Further mediation regression analyses explored potential influence of engagement variables on other independent variables, to understand the prediction of weight change, and a Sobel test examined the significance of the mediation. Significance tests were two-sided at significance $\mathrm{p}<0.05$. Statistical analyses were performed using Minitab V.17 and SPSS V.21 software.

\section{Power analysis}

Sample size was determined by using the estimated SD of change in body mass index (BMI) from an intervention study of patients with hyperglycemia $(n=75)$. A SD of $1.49 \mathrm{~kg} / \mathrm{m}^{2}$ and $\alpha$ of 0.05 produced a final sample of study participants of 44 at $90 \%$ power, to identify a minimum detectable difference in change in BMI of $0.8 \mathrm{~kg} / \mathrm{m}^{2}$ in a one-sample t-test.

\section{RESULTS}

Baseline characteristics of recruited participants, nonstarters, starters, and completers are shown in the table 1. 
Of 121, 78 were non-starters. In both groups, non-starters and starters, the majority of the sample was female, but the proportion was significantly higher in the starters. Starters were also significantly older than non-starters. Baseline weight and height were not different between groups. Approximately $85 \%$ of the starters were female, with a mean age of 51 years at recruitment. All starters were overweight or obese at baseline, with mean weight of $96 \mathrm{~kg}$ and BMI of $35 \mathrm{~kg} / \mathrm{m}^{2}$. No significant differences were observed between starters and completers.

Weight loss and BMI change at 16 and 24 weeks were significant (table 1), with $56 \%$ of starters and $64 \%$ of completers losing over $5 \%$ body weight at 24 weeks $(6.58 \%$ and $7.5 \%$ mean weight loss, respectively). Weight loss increased steadily over time, but there was no significant difference between 16 and 24 weeks. Ad hoc ANOVA tests indicated that weight loss was significant at 16 weeks for starters $(\mathrm{M}=-5.40, \mathrm{SD}=4.43$, $\mathrm{p}<0.001, \mathrm{~d}=1.22)$ and completers $(\mathrm{M}=-6.00, \mathrm{SD}=4.34$, $\mathrm{p}<0.001, \mathrm{~d}=1.38)$. Weight loss was also significant at 24 weeks from baseline in starters $(\mathrm{M}=-6.22, \mathrm{SD}=5.00$, $\mathrm{p}<0.001, \mathrm{~d}=1.24)$ and completers $(\mathrm{M}=-7.01, \mathrm{SD}=4.83$, $\mathrm{p}<0.001, \mathrm{~d}=1.45)$. Participants showed a high level of engagement, with $84 \%$ of the sample completing nine lessons or more (CDC standard).

In-app activities reflecting engagement significantly predicted weight loss among starters and completers. Backward regression analysis examined the impact of various in-app actions on percent weight loss at 6 months for starters (table 1). User actions that significantly predicted these variables were the number of weekly weigh-ins and the number of meals logged. Number of group posts remained in the second-to-last model as an insignificant predictor of percent weight loss. The significant variables explained $43 \%$ of the variance. For every SD increase in meals logged, percent weight loss increased by 0.36 SDs $(\beta=0.357, p=0.016)$. Every SD increase in weigh-ins increased weight loss by 0.39 SDs $(\beta=0.389, p=0.009)$. Mediation regression analyses further explained the chain of relations between group posts, meals logged and percent weight loss.

Mediation results are illustrated in figure 2. In the first model, path a, group posts were significantly associated with food logging $\left(\mathrm{F}(1: 42)=4.99, \mathrm{R}^{2}=0.11, \mathrm{p}=0.031\right)$, such that those who made group posts logged 2.33 additional meals. Group posts were significantly associated with

Table 1 Baseline, weight change, and engagement characteristics of study starters and completers

\begin{tabular}{|c|c|c|c|}
\hline & $\begin{array}{l}\text { Non-starters }(\mathrm{N}=77 / 121) \\
\text { Mean } \pm \text { SD }\end{array}$ & $\begin{array}{l}\text { Starters }(\mathrm{N}=43) \\
\text { Mean } \pm S D\end{array}$ & $\begin{array}{l}\text { Completers }(\mathrm{N}=36) \\
\text { Mean } \pm \mathrm{SD}\end{array}$ \\
\hline \multicolumn{4}{|l|}{ Baseline } \\
\hline Gender, female N (\%) & $54(69.2 \%)^{*}$ & $37(86 \%)$ & $30(83.3 \%)$ \\
\hline Mean age (years) & $46.97 \pm 9.44 \dagger$ & $51.49 \pm 8.30$ & $51.44 \pm 8.48$ \\
\hline Height $(m)$ & $1.68 \pm 0.15$ & $1.65 \pm 0.09$ & $1.66 \pm 0.09$ \\
\hline Weight (kg) & $91.50 \pm 18.21(\mathrm{~N}=29)$ & $96.61 \pm 22.33$ & $96.26 \pm 23.08$ \\
\hline BMI $\left(\mathrm{kg} / \mathrm{m}^{2}\right)$ & $32.55 \pm 6.99(\mathrm{~N}=29)$ & $35.51 \pm 7.38$ & $34.79 \pm 7.33$ \\
\hline \multicolumn{4}{|l|}{16 weeks $\ddagger$} \\
\hline Weight loss (kg) & & $-5.40 \pm 4.43$ & $-6.00 \pm 4.34$ \\
\hline Weight loss (\%) & & $-5.65 \pm 4.34$ & $-6.33 \pm 4.22$ \\
\hline BMl change $\left(\mathrm{kg} / \mathrm{m}^{2}\right)$ & & $-1.99 \pm 1.66$ & $-2.20 \pm 1.63$ \\
\hline \multicolumn{4}{|l|}{24 weeks§ } \\
\hline Weight loss (kg) & & $-6.22 \pm 5.00$ & $-7.01 \pm 4.83$ \\
\hline Weight loss (\%) & & $-6.58 \pm 5.12$ & $-7.50 \pm 4.93$ \\
\hline BMI change $\left(\mathrm{kg} / \mathrm{m}^{2}\right)$ & & $-2.29 \pm 1.87$ & $-2.57 \pm 1.81$ \\
\hline \multicolumn{4}{|l|}{24 week engagement-in-app actions } \\
\hline Meals logged (meals per week) & & $13.93 \pm 6.00$ & $15.28 \pm 5.13$ \\
\hline Exercise (times/week) & & $3.11 \pm 2.34$ & $3.43 \pm 2.34$ \\
\hline Time exercised (minutes/week) & & $126.61 \pm 110.76$ & $141.60 \pm 112.88$ \\
\hline Steps recorded (steps/week) & & $21116.87 \pm 18413.06$ & $24045.97 \pm 18112.21$ \\
\hline Number of weigh-ins (times/week) & & $1.04 \pm 0.93$ & $1.17 \pm 0.96$ \\
\hline Articles read (articles/week) & & $5.11 \pm 2.67$ & $5.86 \pm 2.22$ \\
\hline Group posts (posts/week) & & $0.51 \pm 0.85$ & $0.59 \pm 0.91$ \\
\hline Group comments (comments/week) & & $1.80 \pm 1.77$ & $2.08 \pm 1.79$ \\
\hline Messages to coach (messages/week) & & $3.32 \pm 2.77$ & $3.78 \pm 2.75$ \\
\hline Group likes (likes/week) & & $1.00 \pm 1.71$ & $1.11 \pm 1.80$ \\
\hline
\end{tabular}

Weight change from 16 to 24 weeks was not significant.

${ }^{*} \mathrm{p}=0.036$ between non-starters and starters.

$\mathrm{t} \mathrm{p}=0.008$ between non-starters and starters.

$\ddagger$ All changes from baseline to 16 weeks were significant in starters and completers, $p<0.001, d=1.22$ and 1.38 , respectively.

$\S$ All changes from baseline to 24 weeks were significant in starters and completers, $p<0.001, d=1.24$ and 1.45 , respectively.

BMI, body mass index. 


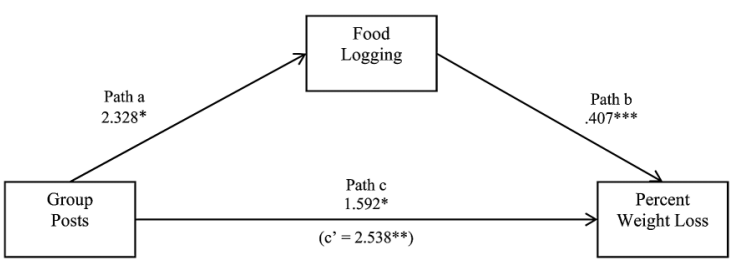

Figure 2 Food logging mediation of group posts on percent weight loss. ${ }^{*} p<0.05,{ }^{* *} p<0.01,{ }^{* \star *} p<0.001$.

percent weight loss $(\mathrm{F}(1: 41)=8.84, \mathrm{p}=0.005)$ in path c. Approximately $17 \%$ of the variance in percent weight loss is explained by group posts, where group posts were a significant unique predictor of percent weight loss $(\beta=2.54, p=0.005)$. In the final model, partial mediation was shown ( path $b$ and $c),(F(2,40)=12.24, p<0.001)$, where the model accounted for $38 \%$ of the percent weight loss, and group posts became a marginally significant predictor of percent weight loss $(\beta=1.59, \mathrm{p}=0.052)$, but meals logged remained significant $(\beta=0.407$, $\mathrm{p}=0.001)$. A Sobel test was marginally significant $(\mathrm{p}=0.057)$, suggesting that meal logging partially mediated the relationship between group posts and percent weight loss.

\section{CONCLUSIONS}

This pilot study, designed to evaluate weight loss by means of a novel NDPP intervention delivered entirely through a smartphone platform, showed 6-month weight loss comparable to the original NDPP and traditional in-person programmes. ${ }^{13}$ ${ }^{14}$ Completers represented $84 \%$ of the sample and lost $7.01 \mathrm{~kg}(15.45 \mathrm{lbs}, 7.50 \%)$ body weight at 24 weeks, surpassing $5-7 \%$ weight loss recommended by the CDC, ${ }^{15}$ and showing a high level of acceptance and programme feasibility. Completers also showed a trend toward higher general engagement and weight loss.

For all users, weekly weigh-ins and meals logged were the main predictors of weight loss, supporting the importance of self-monitoring in weight loss. Group posts alone were a significant predictor of percent weight loss. Since it also remained in the second-to-last backward regression model predicting percent weight loss, further mediation regression analyses were performed. The analyses revealed that meals logged partially mediated the group posts-weight loss relationship. This suggests that meal logging is influenced by group behavior, which ultimately impacts weight loss. Thus, it is important to provide individuals enrolled in a NDPP with not only an extensive food database and ability to $\log$ meals with ease, but also with the social support to maximize logging behavior.

To the best of our knowledge, this is the first fully mobile translation of the DPP. Web-based delivery of an adapted NDPP resulted in high levels of engagement, improvements in HbAlc, and similar but smaller degrees of weight loss. ${ }^{45}$ Mobile health implementation of NDPP appears to be comparable to current community-based programmes and more flexible than web-based implementations. It addresses the major barriers facing the widespread translation of the NDPP in the community setting; including high fixed overhead, fixed locations, and lower levels of engagement and weight loss. Only one study ${ }^{10}$ adapted the NDPP to deliver the first part of the curriculum in-person and the remaining sessions through a mobile app, and found $6.8 \%$ weight loss at 5 months. Our findings support the effectiveness of a uniquely mobile intervention, producing weight loss comparable to studies with high engagement with potential for scalable population health management.

A limitation of this study is the absence of a control group and a limited 6-month duration. However, our results are comparable to 6-month outcomes (weight loss and glucose) in the DPP, which have been shown to be predictive of 3-year diabetic risk reduction. ${ }^{16}$ Second, this study did not measure HbAlc, but others have found no significant changes in HbAlc at $16^{5}$ or 24 weeks. ${ }^{10}{ }^{16}$ A larger clinical trial of mobile DPP with an in-person NDPP control group is recommended to establish intervention efficacy, identify behaviors that increase participant engagement, and assess physiological markers of diabetes risk longitudinally.

In conclusion, this pilot demonstrates scalability and feasibility of a novel mobile NDPP intervention with weight loss comparable to online and gold standard in-person core and postcore interventions. Future longitudinal studies are warranted to verify this study's findings.

Acknowledgements The authors would like to thank all the participants in this study. This study would not have been possible without the coaches Peter Athans, MS; Jennifer Major, MS, RD; and Steven Keem, MS (Noom). The authors are also grateful to David González-Barreto, PhD (University of Puerto Rico-Mayagüez) for his assistance and input with statistical analyses, and to Kayla Reynolds, MS (Curriculum and Content Department at Noom) for her editorial assistance.

Contributors TT-R wrote the manuscript and conducted data analyses. AM is the principal investigator. AM co-wrote the manuscript and conducted data analyses. AM is also the guarantor of this work and, as such, had full access to all the data in the study and takes responsibility for the integrity of the data and the accuracy of the data analysis. CR is the research coordinator, reviewed the manuscript, and oversaw the conduct of the study. MW is the coach manager, provided oversight to coaching and training with AM, and reviewed the manuscript. KF provided medical input in the study development, and co-wrote and reviewed the manuscript.

\section{Competing interests None declared.}

Ethics approval An advisory review Institutional Review Board (IRB) letter was obtained after study completion stating the study protocol would have been approved.

Provenance and peer review Not commissioned; externally peer reviewed.

Data sharing statement Owing to confidentiality agreements with research collaborators, supporting data can only be made available to bona fide researchers subject to a non-disclosure agreement on agreement by both parties. Details of the data and how to request access are available by contacting research@noom.com.

Open Access This is an Open Access article distributed in accordance with the Creative Commons Attribution Non Commercial (CC BY-NC 4.0) license, 
which permits others to distribute, remix, adapt, build upon this work noncommercially, and license their derivative works on different terms, provided the original work is properly cited and the use is non-commercial. See: http:// creativecommons.org/licenses/by-nc/4.0/

\section{REFERENCES}

1. Dunkley AJ, Bodicoat $\mathrm{DH}$, Greaves $\mathrm{CJ}$, et al. Diabetes prevention in the real world: effectiveness of pragmatic lifestyle interventions for the prevention of type 2 diabetes and of the impact of adherence to guideline recommendations: a systematic review and meta-analysis. Diabetes Care 2014;37:922-33.

2. Knowler WC, Barrett-Connor E, Fowler SE, et al. Reduction in the incidence of type 2 diabetes with lifestyle intervention or metformin. N Engl J Med 2002;346:393-403.

3. Diabetes Prevention Program Research G. Long-term effects of lifestyle intervention or metformin on diabetes development and microvascular complications over 15-year follow-up: the Diabetes Prevention Program Outcomes Study. Lancet Diabetes Endocrinol 2015;3:866-75.

4. Sepah SC, Jiang L, Peters AL. Long-term outcomes of a web-based diabetes prevention program: 2-year results of a single-arm longitudinal study. J Med Internet Res 2015;17:e92.

5. Sepah SC, Jiang L, Peters AL. Translating the diabetes prevention program into an online social network: validation against CDC standards. Diabetes Educ 2014;40:435-43.

6. Block G, Azar KM, Romanelli RJ, et al. Diabetes prevention and weight loss with a fully automated behavioral intervention by email, web, and mobile phone: a randomized controlled trial among persons with prediabetes. J Med Internet Res 2015;17:e240.

7. Yardley L, Ware LJ, Smith ER, et al. Randomised controlled feasibility trial of a web-based weight management intervention with nurse support for obese patients in primary care. Int $J$ Behav Nutr Phys Act 2014;11:67.

8. Kramer MK, Kriska AM, Venditti EM, et al. A novel approach to diabetes prevention: evaluation of the Group Lifestyle Balance program delivered via DVD. Diabetes Res Clin Pract 2010;90:e60-3.

9. Van Name MA, Camp AW, Magenheimer EA, et al. Effective translation of an intensive lifestyle intervention for Hispanic women with prediabetes in a community health center setting. Diabetes Care 2016;39:525-31.

10. Fukuoka $\mathrm{Y}$, Gay $\mathrm{CL}$, Joiner $\mathrm{KL}$, et al. A novel diabetes prevention intervention using a mobile app: a randomized controlled trial with overweight adults at risk. Am J Prev Med 2015;49:223-37.

11. Piette JD, List J, Rana GK, et al. Mobile health devices as tools for worldwide cardiovascular risk reduction and disease management. Circulation 2015;132:2012-27.

12. Pludwinski S, Ahmad F, Wayne N, et al. Participant experiences in a smartphone-based health coaching intervention for type 2 diabetes: a qualitative inquiry. $J$ Telemed Telecare 2016;22:172-8.

13. Ackermann RT, Finch EA, Brizendine $\mathrm{E}$, et al. Translating the Diabetes Prevention Program into the community. The DEPLOY Pilot Study. Am J Prev Med 2008;35:357-63.

14. Marrero DG, Palmer KN, Phillips EO, et al. Comparison of commercial and self-initiated weight loss programs in people with prediabetes: a randomized control trial. Am J Public Health 2016;106:949-56.

15. CDC. National Diabetes Statistics Report: estimates of diabetes and its burden in the United States, 2014. Atlanta, GA: U.S. Department of Health and Human Services, 2014.

16. Maruthur NM, Ma Y, Delahanty LM, et al. Early response to preventive strategies in the Diabetes Prevention Program. $J$ Gen Intern Med 2013;28:1629-36. 